\title{
Sistematização da assistência de enfermagem no atendimento à mulher vítima de violência
}

\author{
Systematization of nursing assistance in assistance to women victims of violence
}
Sistematización de la asistencia de enfermería para ayudar a las mujeres víctimas de violencia

Karine Barbosa Porto ${ }^{1 *}$, Luciana Rodrigues de Alencar ${ }^{1}$, Sandra Nara Marroni ${ }^{1}$, Márcia Andréa Marroni $^{1}$, Iran Miranda Silva ${ }^{1}$, Claudia Christina Ribeiro Guimarães Neri de Magalhães ${ }^{1}$, Denise Soares de Alcântara' ${ }^{1}$, Halline Cardoso Jurema², Erivan Elias Silva de Almeida ${ }^{1}$.

\section{RESUMO}

Objetivo: Descrever a assistência de enfermagem à mulher vítima de violência. Métodos: Trata-se de uma revisão sistemática, seguindo a metodologia descrita por PRISMA, utilizando artigos originais indexados nas bases de dados Biblioteca Virtual em Saúde, Literatura Latino-Americana e do Caribe em Ciências da Saúde, Banco de Dados em Enfermagem e Google Scholar. O levantamento dos dados foi realizado durante o mês de fevereiro de 2020. Resultados: Após a seleção seguindo os critérios de inclusão e exclusão, chegou-se à amostra final composta por 08 artigos. Os resultados foram apresentados e discutidos em três categorias. A primeira trata-se dos aspectos relacionados a Violência Contra a Mulher, a segunda categoria aborda sobre O Atendimento às Vítimas de Violência nos serviços de saúde e a terceira categoria dispõe sobre a Sistematização da Assistência de Enfermagem a mulher vítima de violência. Considerações finais: $A$ assistência de enfermagem a mulher vítima de violência deve envolver o acolhimento, diálogo, escuta qualificada e empatia, além da participação de outros profissionais de saúde, para a identificação, notificação e tratamento das clientes, conforme preconizado em lei.

Palavras-chave: Assistência integral à saúde, Violência contra a mulher, Prevenção primária, Cuidados de enfermagem.

\section{ABSTRACT}

Objective: To describe nursing care for women victims of violence. Methods: This is a systematic review, following a methodology applied by PRISMA, using original articles indexed in the Virtual Health Library, Latin American and Caribbean Literature in Health Sciences databases, Nursing Database and Google Scholar. The data survey was carried out during February 2020. Results: After the selection following the inclusion and exclusion criteria, the final sample was made up of 08 articles. The results were presented and discussed in three categories. The first deals with aspects related to Violence Against Women, in the second category covered on Assistance to Victims of Violence in health services and in the third category, available on the Systematization of Nursing Care for women victims of violence. Final considerations: Nursing care for women who are victims of violence should involve welcoming, dialogue, qualified listening and empathy, in addition to the participation of other health professionals, for the identification, notification and treatment of clients, as required by law.

Keywords: Comprehensive health care, Violence against women, Primary prevention, Nursing care.

\footnotetext{
1Universidade de Gurupi (UNIRG), Gurupi - TO. *E-mail: karinegatinhapink@hotmail.com
}

${ }^{2}$ Faculdade Venda Nova do Imigrante (Faveni), Venda Nova do Imigrante - ES. 


\section{RESUMEN}

Objetivo: Describir los cuidados de enfermería para mujeres víctimas de violencia. Métodos: Esta es una revisión sistemática, siguiendo una metodología aplicada por PRISMA, utilizando artículos originales indexados en la Biblioteca Virtual de Salud, las bases de datos de Literatura Latinoamericana y del Caribe en Ciencias de la Salud, la Base de Datos de Enfermería y Google Scholar. La encuesta de datos se realizó durante febrero de 2020. Resultados: Después de la selección siguiendo los criterios de inclusión y exclusión, la muestra final estaba compuesta por 08 artículos. Los resultados fueron presentados y discutidos en tres categorías. El primero trata los aspectos relacionados con la violencia contra las mujeres, en la segunda categoría cubierta en Asistencia a las víctimas de violencia en los servicios de salud y en la tercera categoría, disponible en la Sistematización de la atención de enfermería para mujeres víctimas de violencia. Consideraciones finales: La atención de enfermería a las mujeres que son víctimas de violencia debe incluir la bienvenida, el diálogo, la escucha calificada y la empatía, además de la participación de otros profesionales de la salud, para la identificación, notificación y tratamiento de clientes, según lo exige la ley.

Palabras clave: Atención integral de salud, Violencia contra la mujer, Prevención primaria, Atención de enfermería.

\section{INTRODUÇÃO}

Por muito tempo, a violência era vista apenas como uma temática que pertencia ao âmbito do Direito e da Segurança Pública, em que deveria ser tratada somente nas instituições pertencentes e/ou vinculadas à órgãos judiciais. Assim, as instituições e consequentemente os profissionais da área da saúde, não possuíam uma participação direta a essas pessoas que eram vitimadas por atos de violência, estando essas, diante de diversos estigmas e exposições sociais.

Somente na década de 1990, a violência foi incorporada, em todo o mundo, como sendo uma problemática da Saúde Pública, em consequência dos indicadores sintomáticos causados aos indivíduos acometidos em seus aspectos físicos, psíquicos e morais, tornando-o sujeito necessitado dos serviços de saúde (SOUZA AEB, et al., 2018).

Conforme a Organização Mundial da Saúde (OMS) (2002), a violência é definida como "o uso de força física ou do poder, em ameaça ou na prática, contra si próprio, outra pessoa, grupo ou comunidade, que resulte em sofrimento, morte, dano psicológico, desenvolvimento prejudicado ou privação." Já a violência exercida contra a mulher configura-se como qualquer ação ou omissão que the cause alguma lesão, sofrimento físico, sexual, psicológico, dano moral ou patrimonial, ou o óbito (NETTO LA, et al., 2018).

Através de uma pesquisa multicêntrica, em 10 países, realizada pela OMS, foi possível observar que 15 a $71 \%$ das mulheres do mundo já foram vítimas de alguma forma de violência física, verbal ou sexual. O que evidencia que este é um problema recorrente, principalmente nos países subdesenvolvidos, como por exemplo, o Brasil (SOUZA MMS, OLIVEIRA MVP e JESUS LKA, 2016).

O assunto, no Brasil, é tratado como uma questão de saúde pública, com ações que visam envolver toda a equipe multidisciplinar, com cuidados direcionados às mulheres que são vítimas desse tipo de violência. Porém, é notável que ainda existem inúmeros desafios, principalmente no que diz respeito às ações para a identificação e acolhimento dos casos nos diversos tipos de serviços de saúde, e ainda, na articulação de intervenções preventivas e curativas (PAIXÃO LABN, 2014; LIMA LAA, et al., 2017).

A Atenção Primária à Saúde é um dos principais setores da saúde pública do país, que busca atender as mulheres em situação de violência, a partir do reconhecimento dos casos suspeitos e confirmados. Essas ações fazem parte de um novo atendimento especializado do Sistema Único de Saúde (SUS), que agora é garantido pela Lei 13.427/2017, que garante, entre outros direitos, o acompanhamento psicológico e cirurgias plásticas reparadoras, se for o caso. Além disso, há também o Programa de Assistência Integral à Saúde da Mulher (PAISM), criado pelo Ministério da Saúde em 1984, colaborando de maneira direta para com o acolhimento dessas clientes, na prática assistencial. 
É evidente que a equipe de enfermagem, junto a outros profissionais de saúde, necessita voltar à atenção para a prevenção da violência contra as mulheres. Caso a violência já tenha ocorrido, a equipe deverá atender as vítimas, com apoio e suporte de confiança para haver o cuidado e assistência às angústias, sentimentos de humilhação, medos e receios (PAIXÃO LABN, 2014; SALDANHA BL, 2013).

A importância do acolhimento é evidente, pois colabora de forma direta com a o desenvolvimento de uma relação de confiança entre a cliente e a equipe multiprofissional, o que garante respostas mais resolutivas aos problemas identificados através da primeira consulta (SANTOS J, et al., 2014).

Por isso, os profissionais de enfermagem, devem estar sempre capacitados para promover um atendimento de qualidade e bem articulado às mulheres vítimas de violência, para que elas se sintam seguras, acolhidas, respeitadas e acima de tudo, tenham as suas necessidades individuais atendidas. Estando sempre orientadas pelos instrumentos básicos propostos nas políticas públicas de saúde e na legislação vigente, para a devida proteção as vítimas e ainda a prevenção de possíveis agravos futuros (LIMA LAA, et al., 2017).

Levando em consideração que no Brasil, há uma alta prevalência de violência contra a mulher, sendo este um dos problemas mais prevalentes de Saúde Pública, a prática ainda tem mostrado que se faz necessário discutir os meios de cuidar em enfermagem à mulher vítima de violência, buscando aprofundar nos aspectos que dizem respeito à atuação desses profissionais, de modo que esse atendimento se faça de forma singular e específica (ACOSTA DF, et al., 2017).

Nesse sentido, se propôs para a realização dessa pesquisa, a seguinte problemática: "Qual a importância do profissional de enfermagem na assistência a mulher vítima de violência, desde o acolhimento, o acompanhamento e a prestação de cuidados?". Sabendo que é de suma importância que os profissionais de enfermagem estejam capacitados para acolher, abordar e prestar os cuidados necessários as mulheres vítimas de violência, o presente estudo se propõe a descrever a assistência de enfermagem à mulher vítima de violência, bem como elencar os principais diagnósticos e intervenções de enfermagem.

\section{MÉTODOS}

A pesquisa seguiu os procedimentos metodológicos descritos na literatura, a qual utiliza uma metodologia sistemática para a elaboração da pergunta de pesquisa; a seleção dos descritores; escolha das bases de dados; definição dos critérios de inclusão e exclusão; a busca na literatura; a seleção dos artigos; a extração dos dados; a avaliação da qualidade metodológica; a avaliação da qualidade das evidências; e a redação e publicação dos resultados, segundo a metodologia descrita por Preferred Reporting Items for Systematic Reviews and Meta-Analyses (PRISMA) (GALVÃO TF, PEREIRA MG, 2014).

Estabeleceu-se a seguinte questão norteadora: "Quais os cuidados prestados pelo profissional de enfermagem a mulher vítima de violência, desde o acolhimento, o acompanhamento e a prestação da assistência?"

A revisão foi realizada, utilizando artigos originais disponíveis nas bases de dados BVS, que abrange outras bases de dados como: LILACS e BDENF. Foi utilizado também o Google Scholar. A busca ocorreu durante o mês de fevereiro de 2020, em artigos publicados entre 2014 e 2020, no idioma português.

Foi utilizada a terminologia em saúde consultada nos Descritores em Ciências da Saúde (DECS), pelos quais se identificaram os respectivos descritores: assistência integral à saúde; violência contra a mulher; prevenção; cuidados de enfermagem. Inicialmente, a identificação dos artigos foi realizada pelo título das publicações encontradas nas bases de dados, conforme a estratégia de busca estabelecida. Em caso de dúvida, foi realizada leitura do resumo e metodologia do estudo. Após esta fase de refinamento, foi realizada a leitura dos resumos ou dos artigos na íntegra, para identificação dos estudos que fariam parte da revisão.

Foram encontradas 113 publicações e, como critérios de inclusão, a pesquisa contemplou artigos em texto completo (do tipo original) de forma gratuita, estudos que abordavam a questão norteadora, com recorte temporal de 2014 a 2020 e estudos disponíveis no idioma português. O recorte temporal estabelecido deu-se pelo interesse em realizar uma revisão com estudos contemporâneos. 
Inicialmente foram excluídos os artigos que estavam fora do recorte temporal, restando 59 estudos, posteriormente foram aplicados os filtros de: idioma e texto completo, sendo assim, 45 estudos restaram nesta etapa, em seguida, foram excluídos os estudos não originais (revisões de literatura), além daqueles que não se relacionavam com a questão de pesquisa, assim para a análise dos resumos e texto completo restaram 30 artigos. No caso de artigos duplicados nas bases de dados, estes foram considerados apenas uma vez. Ao fim, chegou-se a 8 artigos finais para a realização deste estudo (Figura 1).

Figura 1 - Fluxograma PRISMA do processo de identificação e seleção dos artigos para a revisão sistemática sobre a sistematização da assistência de enfermagem no atendimento à mulher vítima de violência.

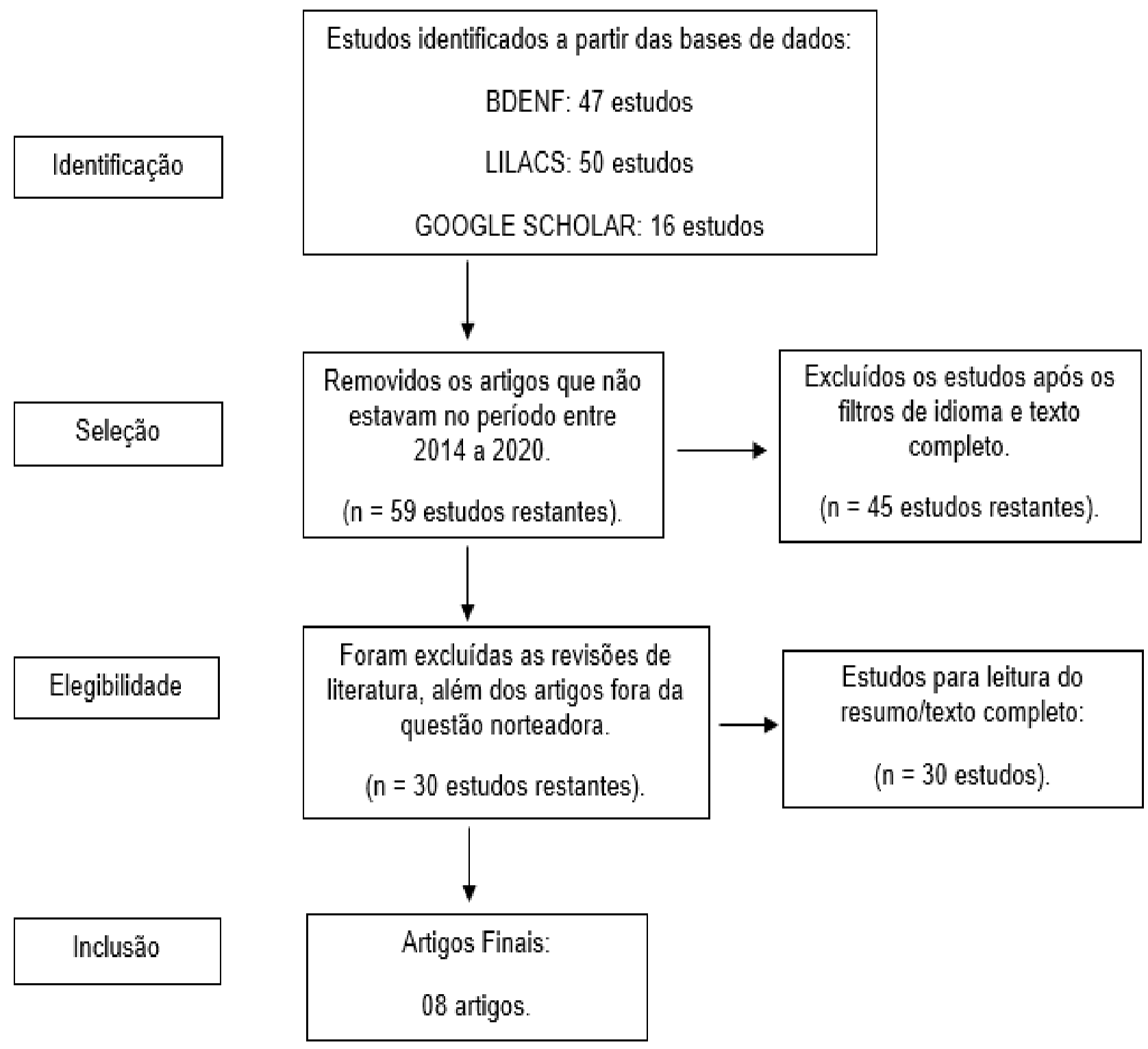

Fonte: Porto KB, et al., 2020.

\section{RESULTADOS}

A amostra final da revisão foi composta por 08 artigos. Para organização desses estudos, os resultados foram categorizados de forma descritiva, sendo analisados com base na literatura, de acordo com o tema, com os seguintes dados: autores/as, ano de publicação, título, objetivo e tipo de pesquisa (Quadro 1). 
Quadro 1 - Apresentação dos artigos selecionados, de acordo com os autores, ano de publicação, título, objetivo e tipo de pesquisa.

\begin{tabular}{|c|c|c|c|c|}
\hline Autores/as & Ano & Título & Objetivo & $\begin{array}{l}\text { Tipo de } \\
\text { pesquisa }\end{array}$ \\
\hline Santos J, et al. & 2014 & $\begin{array}{c}\text { Atuação da equipe de } \\
\text { enfermagem em unidades de } \\
\text { saúde da família no } \\
\text { atendimento à mulher vítima } \\
\text { de violência. }\end{array}$ & $\begin{array}{c}\text { Identificar a atuação da equipe } \\
\text { de enfermagem em Unidades } \\
\text { de Saúde da Família no } \\
\text { atendimento à mulher vítima de } \\
\text { violência, a partir dos } \\
\text { conhecimentos que possuem e } \\
\text { de suas percepções em torno } \\
\text { do problema. }\end{array}$ & $\begin{array}{l}\text { Exploratório- } \\
\text { descritivo, } \\
\text { de campo, } \\
\text { com } \\
\text { abordagem } \\
\text { quantitativa. }\end{array}$ \\
\hline $\begin{array}{c}\text { Cortes LF e } \\
\text { Padoin SMM. }\end{array}$ & 2016 & $\begin{array}{l}\text { Intencionalidade da ação de } \\
\text { cuidar mulheres em situação } \\
\text { de violência: contribuições } \\
\text { para a Enfermagem e Saúde. }\end{array}$ & $\begin{array}{c}\text { Apreender as motivações da } \\
\text { ação da enfermeira ao cuidar } \\
\text { de mulheres em situação de } \\
\text { violência. }\end{array}$ & Qualitativa. \\
\hline $\begin{array}{l}\text { Rodrigues } \\
\text { WFG, et al. }\end{array}$ & 2017 & $\begin{array}{l}\text { Violência contra a mulher } \\
\text { dentro de um contexto } \\
\text { biopsicossocial um desafio } \\
\text { para o profissional da } \\
\text { enfermagem. }\end{array}$ & $\begin{array}{l}\text { Analisar o cuidado da equipe de } \\
\text { Enfermagem, considerando os } \\
\text { aspectos biopsicossociais, às } \\
\text { mulheres vítimas de violência } \\
\text { hospitalizadas em serviços de } \\
\text { emergência e trauma. }\end{array}$ & $\begin{array}{l}\text { Exploratório } \\
\text { e analítico, } \\
\text { com } \\
\text { abordagem } \\
\text { quati- } \\
\text { qualitativa. }\end{array}$ \\
\hline $\begin{array}{c}\text { Silva NNF, et } \\
\text { al. }\end{array}$ & 2017 & $\begin{array}{l}\text { Atuação dos enfermeiros da } \\
\text { atenção básica a mulheres em } \\
\text { situação de violência. }\end{array}$ & $\begin{array}{l}\text { Identificar como os enfermeiros } \\
\text { da atenção básica atuam diante } \\
\text { dos casos de mulheres em } \\
\text { situação de violência, em um } \\
\text { município no Pará. }\end{array}$ & $\begin{array}{l}\text { Qualitativo, } \\
\text { descritivo. }\end{array}$ \\
\hline Netto LA, et al. & 2018 & $\begin{array}{l}\text { Atuação da enfermagem na } \\
\text { conservação da saúde de } \\
\text { mulheres em situação de } \\
\text { violência. }\end{array}$ & $\begin{array}{c}\text { Analisar, pela ótica da Teoria } \\
\text { de Enfermagem de Levine, o } \\
\text { atendimento da enfermeira às } \\
\text { mulheres que sofreram } \\
\text { violência. }\end{array}$ & Qualitativa. \\
\hline $\begin{array}{l}\text { Santos SC, et } \\
\text { al. }\end{array}$ & 2018 & $\begin{array}{l}\text { Violência contra a mulher: } \\
\text { como os profissionais na } \\
\text { atenção primária à saúde } \\
\text { estão enfrentando esta } \\
\text { realidade? }\end{array}$ & $\begin{array}{l}\text { Compreender como é prestada } \\
\text { a assistência à mulher vítima de } \\
\text { violência, pelas enfermeiras na } \\
\text { atenção primária à saúde } \\
\text { (APS), identificam-se as } \\
\text { condutas, as dificuldades e } \\
\text { possíveis ações de prevenção à } \\
\text { saúde da mulher. }\end{array}$ & $\begin{array}{l}\text { Exploratório } \\
\text { com } \\
\text { abordagem } \\
\text { qualitativa. }\end{array}$ \\
\hline Feltrin B, et al. & 2019 & $\begin{array}{c}\text { Ser enfermeiro e o cuidado a } \\
\text { mulheres vítimas de violência } \\
\text { doméstica: situações } \\
\text { vivenciadas. }\end{array}$ & $\begin{array}{l}\text { Compreender a experiência } \\
\text { vivenciada pelos profissionais } \\
\text { enfermeiros em identificar, } \\
\text { prestar assistência de } \\
\text { enfermagem e encaminhar as } \\
\text { mulheres vítima de violência } \\
\text { doméstica. }\end{array}$ & $\begin{array}{l}\text { Descritivo e } \\
\text { qualitativo. }\end{array}$ \\
\hline $\begin{array}{l}\text { Santos DS, et } \\
\text { al. }\end{array}$ & 2019 & $\begin{array}{l}\text { Violência doméstica contra a } \\
\text { mulher: visão de enfermeiros } \\
\text { pós-graduandos em } \\
\text { obstetrícia no Piauí. }\end{array}$ & $\begin{array}{c}\text { Conhecer a visão de } \\
\text { enfermeiros pós-graduandos } \\
\text { em obstetrícia sobre a violência } \\
\text { contra a mulher. }\end{array}$ & $\begin{array}{l}\text { Descritivo, } \\
\text { exploratório } \\
\text { e de } \\
\text { abordagem } \\
\text { qualitativa. }\end{array}$ \\
\hline
\end{tabular}

Fonte: Porto KB, et al., 2020. 
Os estudos tiveram como população alvo: enfermeiros, a equipe de enfermagem e discentes do curso de pós-graduação em obstetrícia. Em relação aos cenários dos estudos, estes foram realizados, de maneira geral, em serviços de saúde que englobaram o Centro Obstétrico, Pronto Socorro, Clínica Médica e Cirúrgica, além de Unidades de Saúde da Família (Atenção Primária a Saúde), e um Centro Universitário de caráter privado.

\section{DISCUSSÃO}

A violência contra a mulher, é qualquer ato ou comportamento que esteja baseado ao gênero, e que venha a provocar agravos de caráter físico, sexual e/ou psicológico. No Código Penal, esse tipo de violência já é julgado como um crime e ganhou notoriedade a partir de 2006, com a criação da Lei $n^{\circ} 11.340$, conhecida popularmente como a Lei Maria da Penha. Este ato criminoso, na grande maioria das vezes, é efetuado por companheiro/namorado/marido, familiares, ou até mesmo, vizinhos mais próximos (LIMA LAA, et al., 2017).

De acordo com Santos SC, et al. (2018), a alta predominância dos índices de infrações de violência contra a mulher, tem como infrator o seu próprio parceiro ou indivíduo próximo, o que ficou evidenciado em um levantamento executado em 2012, pela OMS, mostrando que esses indivíduos são os maiores responsáveis por homicídios em mulheres, equivalendo entre 40 a $70 \%$ do número de casos.

Assim, segundo Santos J, et al. (2014), é importante destacar a necessidade de que todos os profissionais de saúde, busquem, cada vez mais, capacitações a respeito dessa problemática, para que assim, possam utilizar as ferramentas corretas e o discernimento necessário para a identificação dos casos, visando ações que promovam a prevenção e a promoção à saúde dessas mulheres.

A violência contra a mulher está presente em todas as faixas etárias, e isso não é diferente quando se trata das mulheres idosas, que devem ser amparadas pelo Estatuto do Idoso, regulamentado pela Lei $n^{\circ}$ 10.741/2003. Muitos profissionais que trabalham diretamente com este público, de acordo com a literatura, relatam que a violência doméstica é causada por cuidadores, muitas das vezes, estressada e despreparada. E que as mulheres idosas vítimas desses maus tratos já possuem um histórico de ocorrências de violências vividas (BRASIL, 2017).

Ainda são identificadas muitas fragilidades de âmbito técnico-profissional e organizacional, desde a área da saúde, a área jurídica e policial. Fora que, por relacionar-se a um fato de caráter histórico e cultural, o acolhimento e atendimento às mulheres, de maneira geral, que são vítimas desse ato de violência, são ainda rotulados por diferentes crenças e pré-julgamentos que dificultam e atrapalham a atuação dos profissionais na prestação de uma assistência eficaz (RODRIGUES WFG, et al., 2017).

Conforme foram citados anteriormente, tais etapas fazem parte do que é regulamentado por meio da Lei $n^{\circ}$ 11.340/2006 que foi alterada pela Lei $n^{\circ}$ 13.427/2017. Esta lei faz alterações no art. $7^{\circ}$ da Lei $n^{\circ}$ 8.080/90, que "dispõe sobre as condições para a promoção, proteção e recuperação da saúde, a organização e o funcionamento dos serviços correspondentes, para inserir, entre os princípios do Sistema Único de Saúde (SUS), o princípio da organização de atendimento público específico e especializado para mulheres e vítimas de violência doméstica em geral" (BRASIL, 2017).

Ou seja, a lei estabelece que em todo o território nacional devem-se garantir todos os direitos da mulher, com o devido planejamento e implementação das redes de apoio, através por meio de programas de saúde para cuidar das vítimas e assim reduzir os índices de criminalidade no país.

Outro importante fator que consolidou maiores avanços no Programa de Assistência Integral à Saúde da Mulher (PAISM), foi a Política Nacional de Atenção Integral à Saúde da Mulher (PNAISM), pois esta trouxe a redefinição da agenda que diz respeito à saúde da mulher, ampliando o leque de ações e incluindo a assistência à mulher vítima de violência doméstica e sexual (BRASIL, 2017).

A Lei de $n^{\circ} 10.778$ estabelece a notificação compulsória, em todo o território nacional, nos casos de violência contra a mulher que forem atendidas em serviços de saúde públicos ou privados. A notificação compulsória deve ser obrigatoriamente realizada pelo Enfermeiro, pois se trata de uma ferramenta que permite avaliar os casos de violência doméstica e familiar contra a mulher, ofertando condições para estimar 
a aplicação de investimentos em núcleos de vigilância em saúde e serviços de assistência e cuidados às vítimas, assim como, na promoção, no desenvolvimento e no aprimoramento de redes de proteção (FELTRIN B, et al., 2019).

Para Netto LA, et al. (2018), o atendimento a essas mulheres vítimas de violência, ainda não há um cronograma pré-definido para o acolhimento, entretanto, o que se sabe é que quanto mais qualificados estiverem os profissionais, mais condições de estabelecer uma relação de cuidado, que superem as ações técnicas, com a criação de um elo de confiabilidade com a cliente. É importante ressaltar que este processo não acontece de maneira esporádica, mas através da interação, disponibilidade e confiança entre o profissional enfermeiro e a paciente.

É preciso que este profissional esteja atento e busque o desenvolvimento de habilidades, que não estejam fundamentadas apenas na forma como agir, porém, na escuta, no observar e sentir. Para ele, entende-se que cuidar do outro, em sua totalidade, deve incluir a elaboração e aplicação de estratégias de promoção e prevenção que podem ser incrementadas por meio da educação em saúde e com orientações a respeito dos direitos dessas vítimas (CORTES LF e PADOIN SMM, 2016).

Nota-se, que deve ser garantido a todas as mulheres, seja qual for a sua classe, raça, etnia, religião, orientação sexual, renda, cultura, nível educacional ou idade, que estas disponham de todos os direitos que Ihe são fundamentais e inerentes, seguindo um dos princípios do SUS, que preconiza a universalidade de seus serviços (RODRIGUES WFG, et al., 2017).

Desse modo, para Santos DS, et al. (2019), identificaram que o acolhimento dessas mulheres vítimas de violência ainda é um enorme desafio, o que exige de toda a equipe multiprofissional esforços conjuntos, e é claro, em parceria com todos setores sociais para que $\mathrm{o}$ atendimento à estas mulheres, seja realizado de forma humanizada e ética.

Segundo Netto LA, et al. (2018), o combate a violência contra a mulher requer da equipe multidisciplinar, principalmente por parte da Enfermagem, a incorporação de posturas sensíveis para o acolhimento das vítimas. Logo, é preciso que estes profissionais visem a prevenção e o controle dessas situações, para que assim, a mulher vítima de violência se sinta apoiada e confortável para expor sobre a sua situação de vida e saúde.

A equipe de enfermagem, juntamente com outros profissionais de saúde, necessita prestar uma atenção voltada para a prevenção de todas as formas de violência contra as mulheres. Para eles, se o ato criminoso já tiver ocorrido, a equipe multidisciplinar deverá ser capaz de atender às vítimas, com apoio e suporte que desperte confiança para haver a superação das angústias, da vergonha, os sentimentos de humilhação, os medos e os receios (SANTOS J, et al., 2014).

Em contrapartida, para Santos SC, et al. (2018), as equipes de saúde, principalmente as da atenção básica, enfrentam desafios e dilemas (medos e insegurança) para a construção da atenção integral às mulheres em situações de violências. O silêncio delas sobre as situações de violência está relacionado muitas vezes aos agressores serem seus parceiros íntimos e/ou outros familiares.

Em todos os estudos selecionados, os profissionais de enfermagem, de maneira geral, demonstraram conhecimento insuficiente sobre as Normas Técnicas para organizar o atendimento as usuárias vítimas de violência, o que evidenciou a falta de estrutura na rede de atenção, ou seja, de uma assistência efetiva que contemple aspectos individuais, institucionais e sociais (PAIXÃO LABN, 2014).

Por isso, é relevante que os profissionais sejam previamente preparados e capacitados, pois assim, terão condições de estabelecer uma relação de cuidado que extrapole as ações técnicas, com estabelecimento de vínculos com a paciente.

O fluxograma de atendimento as mulheres em situação de violência doméstica devem ser realizadas por meio do acolhimento, escuta qualificada, anamnese, o exame físico, o planejamento, a realização da conduta terapêutica e o acompanhamento para identificação do tipo de violência e plano de cuidado (SANTOS SC, et al., 2018). 
Cortes LF e Padoin SMM (2016), observaram que para realizar um cuidado de enfermagem que vise à integralidade, faz-se necessário apreender as motivações para desenvolvê-lo. A fim de que essas possam subsidiar o desenvolvimento de habilidades para a atenção interdisciplinar e intersetorial que visem ao enfrentamento da violência e o entendimento dessa como uma demanda das mulheres e uma questão de saúde pública. Nota-se que apesar desses cuidados descritos inicialmente, na prática, a maioria das mulheres não dizem de imediato que estão vivenciando e enfrentando algum tipo de violência. Por isso, é importante que os profissionais de enfermagem, junto com toda a sua equipe estejam atentos a possíveis sinais.

De acordo com Rodrigues WFG, et al., (2017), dentre os principais sinais e sintomas que o enfermeiro pode observar estão: fragilidade, nervosismo, ansiedade, estado psicológico abalado, angústia, choro, edemas, machucados que não condizem com a história verbalizada. Os enfermeiros relataram que poucas mulheres contam diretamente aos profissionais que sofreram algum tipo de violência doméstica. Desse modo, a mulher que não confirma a suspeita de agressão faz com que os enfermeiros desenvolvam um grupo de investigação, acionando outros profissionais (Agentes Comunitários de Saúde e Assistente Social), e/ou até mesmo familiares para a conclusão dos diagnósticos de violência (FELTRIN B, et al., 2019).

Dessa forma, para que a violência seja de fato enfrentada é oportuno que seja estabelecido a criação de um elo entre a área da saúde, outros serviços de apoio social e a família, delineando-se a capacitação dos profissionais, a formação de serviços de saúde e de equipes multiprofissionais que discutam e implementem a política de atendimento às mulheres em situação de violência com intervenções menos burocrática e mais eficiente em todos os casos de violência.

O Enfermeiro é um dos principais profissionais presentes em instituições de saúde, e ele deve prestar a assistência de forma planejada, embasada em conhecimento técnico científico, exercendo habilidades e competências que favoreçam a compreensão do ser humano em seus aspectos psicológicos, biológicos, espirituais e sociais, garantindo assim, um atendimento humanizado, seguro e resolutivo. Para isso, esse profissional necessita de uma ferramenta dinâmica e eficaz para aperfeiçoar seu trabalho (SANTOS DS, et al., 2019).

Logo, o acolhimento, diálogo, apoio por parte da equipe, proporciona a vítima estabelecer vínculo de confiança, tanto institucional quanto individual, que possibilitam avaliar o histórico da violência e dialogar com a mulher sobre as alternativas e opções de intervenção permitindo-lhe fazer escolhas e encaminhamentos aos órgãos competentes, bem como, incentivar a participação em grupos de apoio, propor acompanhamento psicológico individual ou para o casal caso tenha desejo de manter a relação. As visitas domiciliares também fazem parte das ações de cuidado de enfermagem para cuidar e acompanhar a família, apesar do misto de sentimentos que o profissional possa estar sentindo e de suas crenças isso não deve interferir na continuidade do cuidado prestado.

É importante considerar que uma metodologia a ser seguida é a Sistematização da Assistência de Enfermagem (SAE), visando intervenções direcionadas ao problema buscando resultados através do Processo de Enfermagem (PE), visto que mediante ele o enfermeiro consolida sua atuação na qualidade do cuidado e diminuindo as fragilidades do processo e diretamente atingindo à população assistida em torno do problema (SANTOS DS, et al., 2019) (Quadro 2).

Assim, aliada a assistência de enfermagem e aos cuidados de toda a equipe multiprofissional, deve-se haver o apoio da família e pessoas de confiança, para que no momento em que a mulher decida fazer a denúncia, o caso seja notificado, e a mesma seja encaminhada para o Núcleo de Atendimento à Mulher, onde ela será esclarecida sobre os seus direitos, realizará a queixa, e será informada sobre a lei Maria da Penha (TRIGUEIRO TH, et al., 2014).

Portanto, nota-se que a relevância dos profissionais de enfermagem e demais profissionais de saúde, possuírem a sensibilidade para lidar com essas mulheres. Não é possível resolver essa problemática de forma prática, rápida e eficaz, como é realizado executado em outras situações agravantes à saúde. É preciso que o profissional compartilhe as suas emoções, visando que a mulher se sinta amparada para compartilhar com clareza a realidade que tem vivido, para que assim, seja atendida conforme as demandas de atenção à saúde. 
Quadro 2 - Possíveis Diagnósticos e Intervenções de Enfermagem a mulher vítima de violência.

\begin{tabular}{|c|c|}
\hline Diagnósticos de enfermagem & Intervenções de enfermagem \\
\hline $\begin{array}{l}\text { Integridade da pele prejudicada } \\
\text { Integridade tissular prejudicada }\end{array}$ & $\begin{array}{l}\text { Esclarecer dúvidas quanto ao surgimento de lesões; Avaliar a } \\
\text { irrigação sanguínea e sensibilidade da área lesada; Avaliar a } \\
\text { extensão do acometimento/lesão; Obter a história do paciente, } \\
\text { início e características da lesão; Avaliar a extensão da perda } \\
\text { tecidual. }\end{array}$ \\
\hline Dor crônica & $\begin{array}{l}\text { Apoiar a mulher vítima de violência; Avaliar frequência, } \\
\text { intensidade e localização da dor; Encaminhar para atendimento } \\
\text { especializado; Estimular a confiança no atendimento prestado. }\end{array}$ \\
\hline $\begin{array}{l}\text { Ansiedade } \\
\text { Medo } \\
\text { Fadiga } \\
\text { Desesperança }\end{array}$ & $\begin{array}{l}\text { Acolher a usuária conforme suas necessidades; Oferecer apoio } \\
\text { emocional; Identificar alterações no estilo de vida, conflitos } \\
\text { relacionados a família e/ou com o trabalho; Encorajar a } \\
\text { verbalização dos sentimentos sobre as limitações; Envolver } \\
\text { família/pessoa significativa nos cuidados; Estabelecer relação } \\
\text { de confiança com a paciente; Realizar visita domiciliar; } \\
\text { Proporcionar técnicas de respiração e relaxamento. }\end{array}$ \\
\hline $\begin{array}{l}\text { Nutrição desequilibrada: menor do que } \\
\text { as necessidades corporais }\end{array}$ & $\begin{array}{l}\text { Investigar perda de peso; Realizar acompanhamento dos } \\
\text { hábitos alimentares através da visita domiciliar. }\end{array}$ \\
\hline $\begin{array}{c}\text { Insônia } \\
\text { Padrão de sono prejudicado }\end{array}$ & $\begin{array}{l}\text { Auxiliar a identificação dos determinantes da inadequação do } \\
\text { sono; Avaliar o período do histórico individual e familiar; } \\
\text { Estimular a padronização de horários para atividades diárias e a } \\
\text { realização de atividade física. }\end{array}$ \\
\hline $\begin{array}{l}\text { Baixa autoestima situacional } \\
\text { Isolamento social }\end{array}$ & $\begin{array}{l}\text { Programar monitoramento domiciliar através de visitas; } \\
\text { Estabelecer relação de confiança com a paciente; Estimular a } \\
\text { autoestima da paciente; Favorecer o suporte psicológico para } \\
\text { enfrentamento do quadro; Encaminhar para atendimento } \\
\text { psicológico; Encorajar a verbalização de sentimentos, } \\
\text { percepções e medo; Incentivar interação social; Incentivar a } \\
\text { participação em grupos de apoio; Proporcionar a escuta ativa. }\end{array}$ \\
\hline $\begin{array}{l}\text { Processos familiares disfuncionais } \\
\text { Processos familiares interrompidos } \\
\text { Risco de vínculo prejudicado } \\
\text { Relacionamento ineficaz }\end{array}$ & $\begin{array}{l}\text { Estabelecer relação de confiança com algum familiar; Realizar } \\
\text { visita domiciliar; Acompanhamento/retornos frequentes; Avaliar } \\
\text { fatores de violência familiar; Assegurar respeito aos direitos da } \\
\text { usuária; Investigar o nível de compreensão da família sobre a } \\
\text { situação; Auxiliar a esclarecer valores e expectativas que } \\
\text { podem ser úteis em escolhas importantes; Oferecer assistência } \\
\text { na tomada de decisão. }\end{array}$ \\
\hline Risco de suicídio & $\begin{array}{l}\text { Considerar a hospitalização da paciente com grave risco de } \\
\text { comportamento suicida; Observar o nível de ansiedade; } \\
\text { Proporcionar tranquilidade e conforto; Observar, relatar e } \\
\text { registrar mudanças de humor e comportamentais; Solicitar } \\
\text { permanência de familiar e/ou pessoa significativa no processo } \\
\text { terapêutico; Atentar-se para objetos perigosos e situações de } \\
\text { risco; Observar mudanças de comportamento. }\end{array}$ \\
\hline $\begin{array}{l}\text { Sobrecarga de estresse } \\
\text { Sentimento de impotência }\end{array}$ & $\begin{array}{l}\text { Buscar compreender a perspectiva apresentada da situação } \\
\text { atual; Determinar a capacidade de tomada de decisão da } \\
\text { paciente; Discutir sobre as experiências atuais; Encorajar a } \\
\text { verbalização de sentimentos, percepções e medo; Encorajar o } \\
\text { diálogo; Ussar abordagem calma e segura. }\end{array}$ \\
\hline $\begin{array}{l}\text { Comportamento de saúde propenso a } \\
\text { risco }\end{array}$ & $\begin{array}{l}\text { Realizar visita domiciliar; Manter vínculo com a cliente; } \\
\text { Encorajar familiares/cuidador a participar ativamente dos } \\
\text { cuidados com a cliente; Observar mudanças de comportamento; } \\
\text { Dar apoio emocional a cliente. }\end{array}$ \\
\hline
\end{tabular}

Fonte: Porto KB, et al., 2020. 


\section{CONSIDERAÇÕES FINAIS}

Conclui-se que a assistência de enfermagem deve basear-se na criação do elo de confiança e empatia com a paciente, desde o acolhimento, à escuta ativa, sendo estes meios primordiais para se obter maiores esclarecimentos sobre os sinais e sintomas que podem ser observados precocemente na vítima. E assim, associar o quadro de cada cliente aos possíveis diagnósticos e aplicar as intervenções de enfermagem, referentes a cada situação encontrada. E dessa forma, desenvolver um planejamento efetivo para que a assistência seja humanizada e segura. Logo, por meio da SAE, importante ferramenta para a atuação do enfermeiro, tem-se a possibilidade de organizar o cuidado assistencial, através de ações direcionadas para cada caso. Dessa forma, resultando em uma assistência de qualidade, atendendo a mulher em todos os seus aspectos físicos e emocionais.

\section{REFERÊNCIAS}

1. ACOSTA DF, et al. Cuidado à mulher em situação de violência doméstica: representações de enfermeiras (os) hospitalares. Rev. Eletr. Enf., 2017.

2. BRASIL. Política Nacional de Atenção Integral à Saúde da Mulher - PNAISM. $2^{2}$ Conferência Nacional de Saúde das Mulheres. Brasília; 2017; 63p.

3. CORTES LF, PADOIM SMM. Intencionalidade da ação de cuidar mulheres em situação de violência: contribuições para a Enfermagem e Saúde. Esc. Anna Nery, 2016; 20(4).

4. FELTRIN B, et al. Ser enfermeiro e o cuidado a mulheres vítimas de violência doméstica: situações vivenciadas. Revista Varia Scientia - Ciências da Saúde, 2019; 5(2): 143-152.

5. GALVÃO TF, PEREIRA MG. Revisões sistemáticas da literatura: passos para sua elaboração. Epidemiol. Serv. Saúde. Brasília, 2014; 23(1): 1-3.

6. HERDMAN TH, KAMITSURU S. Diagnósticos de enfermagem da NANDA-I: definições e classificação 2018-2020 [recurso eletrônico] / [NANDA International]; tradução: Regina Machado Garcez; revisão técnica: Alba Lucia Bottura Leite de Barros [et al.]. - 11. ed. - Porto Alegre: Artmed; 2018; 488p.

7. HINKLE JL, CHEEVER KH. Brunner e Suddarth: tratado de enfermagem médico-cirúrgica, volumes 1 e 2 . Tradução Patrícia Lydie Voeux [et al.]. - 13. ed. - Rio de Janeiro: Guanabara Koogan; 2016; 804p.

8. LIMA LAA, et al. Assistência de enfermagem às mulheres vítimas de violência doméstica. Revista de Enfermagem da UFPI, 2017; 6(2): 65-68.

9. NETTO LA, et al. Atuação da enfermagem na conservação da saúde de mulheres em situação de violência. Rev. Min. Enferm. (REME), 2018; 22: 1-8.

10. PAIXÃO LABN. Assistência de enfermagem à mulher vítima de violência Paixão, Leonardo Augusto Bacellar de Novaes. Brasília, 2014.

11. RIBEIRÃO P, et al. Prefeitura de Ribeirão Preto. Secretaria Municipal de Saúde. Departamento de Atenção à Saúde das Pessoas. Divisão de Enfermagem. Diretrizes para Sistematização da Assistência de Enfermagem / Processo de Enfermagem em Ribeirão Preto. Ribeirão Preto: Prefeitura Municipal de Ribeirão Preto; 2019.

12. RODRIGUES WFG, et al. Violência contra a mulher dentro de um contexto biopsicossocial um desafio para o profissional da enfermagem. Rev. Enferm. UFPE online. Recife, 2017; 11(4):1752-8.

13. SALDANHA BL. A enfermagem e o cuidado à mulher vítima de violência sexual. Niterói-SP: [s/n], 2013; 50p.

14. SANTOS DS, et al. Violência doméstica contra a mulher: visão de enfermeiros pós-graduandos em obstetrícia no Piauí. J. Nurs. Health, 2019; 9(3): 1-11.

15. SANTOS J, et al. Atuação da equipe de enfermagem em unidades de saúde da família no atendimento à mulher vítima de violência. Revista Enfermagem Contemporânea, 2014; 3(1): 15-26.

16. SANTOS SC, et al. Violência contra a mulher: como os profissionais na atenção primária à saúde estão enfrentando esta realidade? Revista Saúde e Pesquisa, 2018; 11(2): 359-368.

17. SILVA NNF, et al. Atuação dos enfermeiros da atenção básica a mulheres em situação de violência. Enferm. Foco, 2017; 8(3): 70-74.

18. SOUZA MMS, et al. Violência sexual contra a mulher e o papel do enfermeiro, revisão de literatura. Ciências Biológicas e de Saúde Unit, Aracaju, 2016; 3(3): 257-274.

19. SOUZA AEB, et al. Assistência de enfermagem a mulher vítima de violência: uma revisão integrativa. Universidade Federal de Campina Grande - Centro de Educação e Saúde, Cuité - PB, 2018.

20. TRIGUEIRO TH, et al. O processo de resiliência de mulheres vítimas de violência doméstica: uma abordagem qualitativa. Cogitare Enfermagem, 2014; 19(3). 